\title{
Análise Espacial, Informática e Geoprocessamento Aplicados no Ensino Médio
}

\section{Spatial Analysis, Information Technology and Gepprocessing Apllied in High Schools}

\author{
Samuel Ferreira da Fonseca * \\ Carla Regina Mota Guedes ** \\ Danniella Carvalho dos Santos ***
}

\section{Resumo:}

Atualmente a escola disputa espaço com a informática, jogos eletrônicos e outras tecnologias perante a atenção dos alunos. O uso dos iPods, Smartphones e Tablets por estudantes se tornou tão natural quanto ler e escrever. Desse modo a escola precisa se mobilizar para empregar as ferramentas tecnológicas sem perder de vista as finalidades educacionais. O objetivo deste trabalho é apresentar resultados de dois projetos educacionais que utilizaram análise espacial, geoprocessamento e informática no ensino médio. Trata-se do projeto Geotecnologias na educação: análise, interpretação de dados censitários e representação geográfica (Geotec), executado na E. E. José Maria Pereira, Buritizeiro/MG. O outro é o projeto Diamantina-SIG, executado na E. E. Professor Leopoldo Miranda, Diamantina/MG. Como abordagem metodológica adotou-se a pesquisa bibliográfica e uma análise criteriosa dos referidos projetos (Geotec e Diamantina-SIG) bem como a comparação entre os mesmos. Observou-se que em ambos os projetos os alunos demonstraram pouco conhecimento em relação ao uso da informática. Portanto, iniciativas correlatas tendem a apresentarem resultados promissores neste segmento.

\begin{abstract}
:
Nowadays, the school competes with information technology, electronic games and other technologies student's attention. The use of iPods, Smartphones and tablets by students has become as common as reading and writing. Thus, the school needs to be mobilized to apply technological tools without ever losing sight of the educational objectives. The aims of this study is to present results of two educational projects where was used geoprocessing, information technology and spatial analysis in high schools. It comes from the Geotechnology in education project, analysis, interpretation of census data and geographic representation (Geotec). It was implemented in José Maria Pereira state school, located in Buritizeiro/MG (Brazil).And the other project is Diamantina-GIS, also implemented in Professor Leopoldo Miranda state school, located in Diamantina/MG-Brazil. As a methodological approach adopted to bibliographic research and a thorough analysis of these projects (Geotec and Diamantina-SIG) and the comparison between them. It was observed that in both projects the students demonstrated little knowledge regarding the use of information technology. Therefore, related initiatives tend to present promising results in this segment.
\end{abstract}

* Mestre em Produção Vegetal (Pedologia/Geoprocessamento) pela Universidade Federal dos Vales do Jequitinhonha e Mucuri-UFVJM.

** Mestranda em Geografia pela Universidade Estadual de Montes Claros. Especialista em Gestão e Manejo Ambiental pela Universidade Federal de Lavras.

*** Aluna do Programa de Pós-Graduação em Geografia (mestrado) da Universidade Federal de Uberlândia - UFU

Palavras-chave:

Sistemas de Informação Geográfica, Tecnologias digitais, Ensino de Geografia

Key-Words:

GIS (Geoprocessing, Digital Technology, Geography Teatching 


\section{INTRODUÇÃO}

As técnicas de geoprocessamento, enquanto ferramentas de análise espacial oferecem uma janela de oportunidades para realização de estudos sistemáticos, planejamento urbano e regional, dentre outras demandas (FONSECA et al. 2014). Seja na avaliação de impactos ambientais, análises de saúde pública, estudo da vegetação urbana ou ordenamento territorial, as técnicas de geoprocessamento estão presentes (ROSA, 2005; FONSECA et al. 2014; FONSECA et al., 2016). Estas técnicas devem ser suficientemente compreendidas e aproveitadas em sua totalidade (FONSECA et al. 2013a; FONSECA e MENDONÇA, 2015) de modo a colaborar com o aprendizado dos discentes. O aproveitamento das técnicas de geoprocessamento deve desdobrar-se também na sala de aula do ensino médio, pois a Geografia escolar ainda permanece desvinculada da Geografia universitária, como aponta Pontuschka et al. (2007). Desse modo, o uso das técnicas de geoprocessamento pode proporcionar um elo entre as duas (FONSECA et al. 2013b; LAUDARES, 2014).

A compreensão adequada do geoprocessamento por parte do docente pode despertar nos alunos maior interesse pelas aulas de Geografia no ensino médio. Entretanto, nota-se que poucos professores, que atuam na educação básica dominam apropriadamente as técnicas de geoprocessamento (HOLGADO e ROSA, 2011; FONSECA e MENDONÇA, 2015). Alguns docentes apresentam dificuldades até mesmo em informática básica. Tal realidade reflete os frutos de uma má formação acadêmica, o que nem sempre é culpa do professor (HOLGADO e ROSA, 2011; FONSECA et al. 2013b; FONSECA e MENDONÇA, 2015). Assim posto, essa má formação dificulta a divulgação, aplicação e consolidação das técnicas de geoprocessamento na escola secundária. Situação onde o conhecimento elementar de informática é exigido, pois este conhecimento se estabelece como pré-requisito para manusear um Sistema de Informação Geográfica - SIG, que constitui a plataforma do geoprocessamento (FONSECA et al. 2013c; FONSECA et al. 2014).

As ferramentas computacionais tornaram-se indispensáveis ao ambiente escolar (FITZ, 1999; FONSECA et al. 2013c; FONSECA e MENDONÇA, 2015). Assim sendo, o uso de geoprocessamento, informática e análise espacial, tornam-se necessárias no processo de aprendizagem. Tendo em vista que o professor de Geografia deve trabalhar os conteúdos da disciplina apoiado pela criativi- dade e uso das tecnologias digitais para que a Geografia acadêmica e a Geografia escolar possam se aproximarem o máximo possível (RIBEIRO, 2013). Sabendo que hoje o uso dos iPods, Smartphones e Tablets por estudantes se tornou tão natural quanto ler e escrever. Desse modo, a atualização no perfil do educador em Geografia é uma emergência (ABREU e SANTOS, 2011).

De acordo com vários autores (FITZ, 1999; FONSECA e GUEDES, 2013; FONSECA et al. 2013c; FONSECA e MENDONÇA, 2015) a escola precisa revolucionar sua maneira de ensinar Geografia. Deve tornar os conteúdos mais atrativos. Além disso, precisa se aproximar das inovações tecnológicas vigentes, de modo a se tornar estimulante para os discentes como apontam Fonseca et al. (2013b). Nessa direção, o uso de geoprocessamento no ensino médio se constitui uma alternativa eficiente (FONSECA et al. 2013c). Pode tanto produzir conhecimento, quanto elevar a autoestima dos alunos. Fator positivo, pois o desinteresse dos discentes pela Geografia pode ser proveniente da dificuldade na compreensão da mesma ou da distância entre o cotidiano dos estudantes e a Geografia (FITZ, 1999; FONSECA et al. 2013b; FONSECA e MENDONÇA, 2015).

Para Fonseca (2014) embora o desenvolvimento tecnológico e científico seja perceptível, muitas vezes a tomada de decisão ocorre sem o uso das novas tecnologias geográficas em situações que caberiam as mesmas. Portanto, o ensino de geoprocessamento nas escolas poderá responder de forma positiva a essa demanda.

Geoprocessamento corresponde ao uso de ferramentas matemáticas e computacionais para representação do espaço geográfico e suas variadas dinâmicas (FONSECA et al. 2014 e FONSECA et al., 2016). Para estes autores foi, por meio do de $\urcorner$ senvolvimento das técnicas de informática, permitindo representar dados geográficos em ambiente computacional que emergiu o Geoprocessamento.

Vários estudos estão sendo desenvolvidos com enfoque em geoprocessamento, informática, análise espacial e ensino de Geografia. Nessa perspectiva, Singh et al. (2012) analisaram a possibilidade da introdução de geoprocessamento, em escola secundária, em Sabah (Malásia), localidade em que as tecnologias da informação (Informática) estão bem distribuídas. Em Sabah (Malásia) 90\% dos professores de Geografia da educação básica participaram de um curso para uso de geoprocessamento (SINGH et al. 2012). Para estes autores o principal obstáculo ao uso de geoprocessamento no ensino médio em Sabah é a falta de 
software adequado e método que esteja inserido no currículo básico da disciplina Geografia.

Nos Estados Unidos Kolvoord et al. (2011) utilizaram o Google Earth ${ }^{\mathrm{TM}}$ para introduzir conceitos de geoprocessamento no ensino médio. Esses autores observaram que os alunos ampliaram a base conceitual concernente à Geografia. Conforme Patterson (2007) o uso do Google Earth ${ }^{\mathrm{TM}}$ possui um potencial considerável para melhorar os métodos de ensino de Geografia, além de auxiliar os alunos a desenvolver outras capacidades. Afirmação que endossa o trabalho desenvolvido por Kolvoord et al. (2011), bem como o presente trabalho, que mesmo não se apropriando do referido software (Google Earth $^{\mathrm{TM}}$ ) apresenta o uso de tecnologias atuais na escola básica. Além disso, este aplicativo possibilita a realização de análise espacial, uma das funções elementares da Geografia Aplicada.

Girão e Lima (2013) estudaram o uso de imagens diversas no ensino de Geografia. Estes autores trabalharam com alunos do ensino médio e magistério (médio normal) no município de Carpina/PE. Barros e Chaves (2011) apresentaram a aplicação do método fotocomparativo/fotointerpretativo, baseado na observação da paisagem para atualizarem o ensino de Geografia. Estes autores indicaram o referido método como recurso mediador na busca de melhores relacionamentos entre professor/aluno. A partir destas análises entende-se que a abordagem estática e pautada pelo uso do livro, quadro e giz já não pode ser mais a prática na sala de aula, quando a matéria é Geografia.

O objetivo deste trabalho é apresentar resultados de dois projetos educacionais em que foram utilizados geoprocessamento, informática e análise espacial no ensino médio. Trata-se dos projetos Geotecnologias na educação: análise, interpretação de dados censitários e representação geográfica (Geotec) e Diamantina-SIG. Ambos utilizam as novas tecnologias (geoprocessamento e informática) e foram desenvolvidos em escolas da rede estadual não contando, portanto com incentivos financeiros.

\section{MATERIAL E MÉTODOS}

O caminho metodológico inclui pesquisa bibliográfica pertinente ao uso de geoprocessamento no ensino de Geografia, bem como relacionada à implantação de projetos educacionais. $\mathrm{O}$ resumo dos procedimentos metodológicos está exposto na Figura 1.
Pesquisa bibliográfica (geoprocessamento e ensino de Geografia)

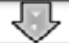

Elaboração, planejamento e participação nos projetos: Geotec e Dimantina-SIG

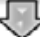

Análise e discussão dos resultados dos projetos estudados.

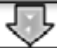

Breve comparação entre os dois projetos estudados

\section{$\sqrt{3}$}

Conclusões: pontos positivos enegativos de cada projeto

Figura 1: Fluxograma apresentando os principais passos metodológicos Fonte: Organizado por FONSECA, S. F. (2016).

Como observado no fluxograma, este trabalho se subdivide em cinco etapas. Na primeira, foi realizada a pesquisa bibliográfica. Esta pesquisa abordou estudos voltados para uso de geoprocessamento e informática na educação, destacando os trabalhos de Singh et al, (2012); Kolvoord et al. (2011); Fonseca et al. (2013c); Barros e Chaves (2011); Abreu e Santos (2011) e Patterson (2007). Tais estudos subsidiaram a o presente trabalho, tendo em vista a delimitação e a finalidade do mesmo.

$\mathrm{Na}$ segunda etapa, foram apresentados os dois projetos educacionais estudados. $\mathrm{Na}$ terceira, foi realizada a análise e discussão dos resultados dos projetos GEOTEC e Diamantina-SIG. Na quarta, realizou-se uma comparação dos resultados dos projetos com objetivo de verificar a eficácia da aplicação de geoprocessamento, informática e análise espacial no ensino médio. Por fim, foram apresentados os pontos positivos e negativos de cada projeto.

Foram analisados dois projetos que utilizaram geoprocessamento, informática e análise espacial no ambiente da educação básica. Um é o Geotecnologias na educação (Geotec), que foi executado na E. E. José Maria Pereira, Buritizeiro/MG no ano de 2013. O outro é o projeto Diamantina-SIG, desenvolvido em Diamantina/MG, na E. E. Professor Leopoldo Miranda em 2014. Ressaltando que os autores do presente trabalho foram também coordenadores do projeto Geotec, portanto participaram da elaboração, planejamento e execução do mesmo. O primeiro autor foi coordenador do projeto Diamantina-SIG participando de todas as etapas neces- 
sárias deste. Uma breve apresentação dos projetos supracitados é apresentada a seguir.

\section{Projeto Geotec}

O projeto Geotec foi elaborado em Fevereiro de 2013. Teve por objetivo inserir geotecnologias na educação básica. No mesmo participaram cinco (5) alunos do último ano do ensino médio e as atividades se desenvolveram no laboratório de Informática da E. E. José Maria Pereira, em Buritizeiro/MG. A escolha dos alunos se deu por indicação da professora de Geografia, que os avaliou segundo três critérios: comportamento em sala de aula, frequência e pontuação na disciplina. As atividades foram realizadas fora do horário de aula. Os alunos estudavam pela manhã, então foi decidido que o projeto funcionaria à tarde. Assim ocorreu.

As atividades obedeceram uma sequência sistematizada:

I - Os alunos tiveram contato com literatura científica (fato inexistente no ensino médio) por meio de livros e artigos da área de geoprocessamento;

II - Foram apresentados aos estudantes sites confiáveis para pesquisa e levantamento de dados (IBGE cidades, Fundação João Pinheiro-FJP), além de mostrar aos mesmos o endereço eletrônico da Plataforma Lattes, incentivando-os à pesquisa;

III - Foi realizado o mapeamento das árvores que estavam localizadas dentro da escola e de mudas que foram plantadas no Balneário do Córrego das Pedras. Para tanto, foi utilizado aparelho receptor de sinal GPS. Nessa etapa, a compreensão do uso e aplicação da geografia ficou ainda mais explícita;

IV - Os alunos realizaram a aquisição e tabulação de dados censitários via internet (nos sites oficiais do governo brasileiro - IBGE e FJP);

$\mathrm{V}$ - Os discentes elaboraram os mapas coropléticos usando degradê (gradação de cores). Nessa etapa utilizaram o aplicativo ArcGIS 9.3;

VI - Por último, ao término da carga horária do Geotec, apresentaram uma síntese do projeto para os demais alunos da turma a qual participavam.

Foram aplicadas atividades com uso do receptor de sinal GPS (Sistema de Posicionamento Global), com o qual os alunos realizaram a marcação de pontos de localização de árvores no lote da escola e no Balneário do Córrego das Pedras. (Figura 3). Explicações prévias e orientações foram dirigidas aos alunos que, manusearam o aparelho GPS para marcação de pontos onde havia árvores da escola. Essa tarefa marca a necessária interação entre conteúdo teórico e prático. Uma vez mencionada a magnitude da geografia e suas potencialidades o contato com as novas tecnologias geográficas (GPS, softwares de geoprocessamento) pode contribuir para a orientação profissional dos alunos, apresentando mais uma opção de mercado.

\section{Projeto Diamantina - SIG}

O projeto Diamantina - SIG foi elaborado com a finalidade de inserir noções básicas de geoprocessamento na escola por meio de atividades extraclasse. O projeto foi desenvolvido na E. E. Professor Leopoldo Miranda, localizada no centro de Diamantina/MG. Em 2014 essa escola participava do programa "Reinventando o Ensino Médio", isso foi uma oportunidade para inserção do projeto na mesma. Foram selecionados 10 (dez) alunos indicados pelos professores. Destes, 5 (cinco) cursavam Empreendedorismo e 5 (cinco), Tecnologia da Informação - TI. Como esperado, os que participavam do curso de TI obtiveram maior êxito nas atividades. Todos os alunos estavam concluindo o primeiro ano científico.

Neste projeto a subdivisão das atividades se deu da seguinte maneira:

I - Introdução à pesquisa sobre os conceitos de geoprocessamento e conhecimento dos sites oficiais (IBGE, FJP, IPEA). Nessa etapa os alunos conheceram melhor os conceitos de pesquisa por meio eletrônico;

II - Apresentação das noções gerais de Estatística Descritiva (fator que levou três alunos a desistirem do projeto, permanecendo somente sete);

III - Introdução às planilhas eletrônicas (Excel e Planilha Calc), nas quais foram realizadas as análises de estatística descritiva para melhor compreensão dos mapas que foram gerados. Essa etapa serviu de estímulo ao uso das planilhas eletrônicas;

IV - Apreendidas as noções estatísticas, os alunos elaboraram uma tabela com as estatísticas descritivas referentes aos indicadores estudados, utilizando os comandos dos softwares LibreOffice Calc ${ }^{\circledR}$ e Microsoft Office Excel ${ }^{\circledR}$. Nesta tabela foram inseridos (Amplitude, Desvio padrão, Variância, Média, Moda, Mediana, Coeficiente de Variação, Valor máximo e mínimo da distribuição estudada, neste caso do IDH e Índice Gini dos 51 municípios da Mesorregião Vale 
do Jequitinhonha);

V - A última tarefa foi a inserção dos dados já manipulados em ambiente SIG e a geração dos mapas coropléticos.

Foram comparados os resultados dos projetos supracitados e abordadas as possibilidades que os mesmos poderão gerar para a escola, caso seja possível a institucionalização dos mesmos. Isto é, a possibilidade dos projetos tornarem parte da proposta curricular da matéria (disciplina) Geografia nas referidas escolas.

\section{RESULTADOS E DISCUSSÃO}

Na Malásia, a Geografia é considerada uma ciência seca (dry) de tecnologias, desconhecendo, dessa forma a aplicabilidade desta ciência em sua totalidade (SINGH, 2013). No entanto, este autor propõe a inserção do geoprocessamento na escola básica como proposta de superação deste paradigma. O que mostra o relacionamento da Geografia com as modernas tecnologias da informação e comunicação. Fator correlato ao proposto neste trabalho. Na Figura 2, estão dois integrantes do Projeto Geotec no Laboratório de Informática.

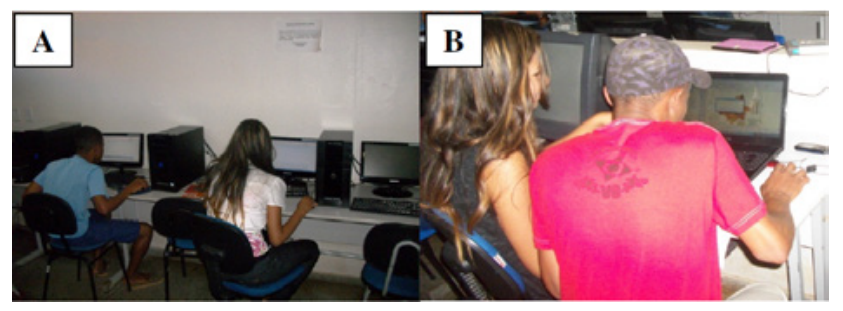

Figura 2 - A: Integrantes do projeto Geotec utilizando a sala de informática B: Alunos editando mapas por meio de Geoprocessamento Fonte: FONSECA, S. F. (2013).

$\mathrm{Na}$ Figura 2A, os alunos estão utilizando a internet para visualizar a Plataforma Lattes. Observou-se que os mesmos desconheciam o significado mais apropriado para pesquisa. Para os estudantes esse termo era sinônimo de Wikipédia, ou qualquer Blog, em que o tema que lhes interessavam poderia ser encontrado. Na Figura 2B, alunos utilizando geoprocessamento no laboratório de informática. Vale ressaltar que as atividades desenvolvidas no laboratório de informática muitas vezes não são bem-sucedidas, pois, a velocidade da internet é baixa, e quando coopera, os alunos sentem-se perdidos quanto ao que pesquisar. Parece haver certo distanciamento entre professores e pesquisa. O que pode ser fruto de insatisfação profissional, de formação acadêmica deficiente (como ocorre na maioria dos cursos de licenciatura em geografia), falta de tempo suficiente para elaborar um roteiro sistemático de pesquisa ou ainda da própria personalidade do professor, que não possui interesse em pesquisar nem se relaciona bem com as novas tecnologias.

$\mathrm{Na}$ Figura 3, duas alunas utilizam receptor GPS para georreferenciamento dos espécimes arbóreos plantados no Balneário do Córrego das Pedras. Essa tarefa, a nosso ver gera novas expectativas em relação à geografia, pois se percebe a falta de ênfase em relação ao uso dessa matéria no cotidiano.

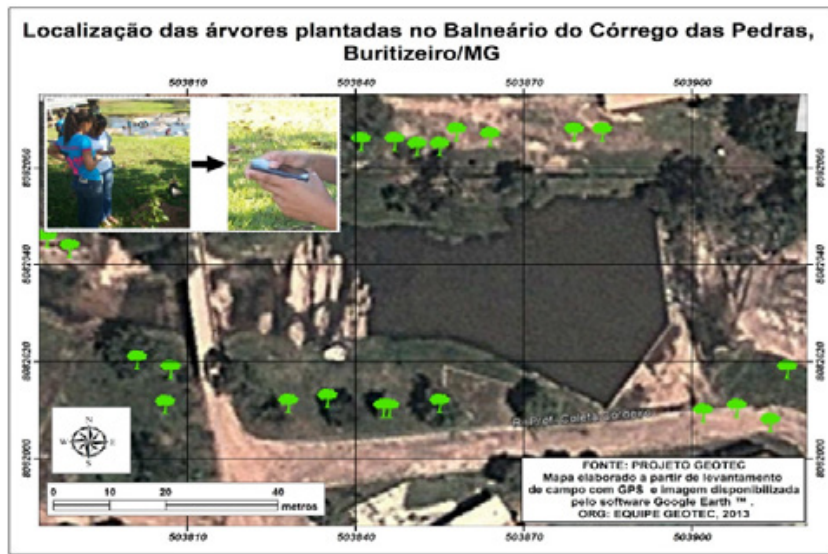

Figura 3: Mapa gerado pelos pontos georreferenciados no Balneário do Córrego das Pedras. No canto superior esquerdo da figura se observa duas alunas trabalhando com aparelho GPS.

Fonte: FONSECA, S. F. (2013).

Foram gerados mapas temáticos da microrregião de Pirapora/MG (Figura 4A). Fato que possibilitou aos alunos o desenvolvimento de capacidades próprias ao uso da informática, geoprocessamento e análise espacial. Do mesmo modo, foi possível ampliar a compreensão a respeito da realidade socioeconômica daquela microrregião (FONSECA et al., 2013d). Por meio do Geotec atividades relacionadas à cartografia foram direcionadas para os participantes. Com essas atividades os alunos ampliaram a concepção da geografia para o cotidiano (Figura 4B).

$\mathrm{Na}$ Figura 4A observa-se um mapa coroplético, representando o Índice de Desenvolvimento Humano IDH dos municípios da microrregião de Pirapora/MG. A visualização de mapas temáticos possibilitou aos estudantes que participaram do Geotec maior clareza em relação à análise espacial. Na Figura 4B é apresentado um mapa com visada vertical (fundamental para ampliar a ideia de estereoscopia), mostrando a escola onde os participantes do projeto estudam. Atividades dessa envergadura são de elevada importância para contribuir com a aproximação 
da geografia com o dia-a-dia dos alunos. Auxilia ainda a romper com o paradigma da inutilidade do conhecimento geográfico. A figura 5 mostra a equipe Geotec reunida para dar início às atividades em 2013.

Os alunos que participaram do projeto Geotec demonstraram bom desempenho e aptidão para trabalhar com geoprocessamento.
$\mathrm{Na}$ Figura 6, são apresentadas duas situações. $\mathrm{Na}$ figura 6A, os alunos estão utilizando a sala de informática (laboratório), com acesso à internet, para pesquisar os conceitos elementares de geoprocessamento (pois, foram elaboradas atividades para casa sobre os conceitos mais relevantes de geoprocessamento). Na figura $6 \mathrm{~B}$ os alunos estão acompanhando um colega resolvendo questão de estatística no quadro (também na sala de informática).

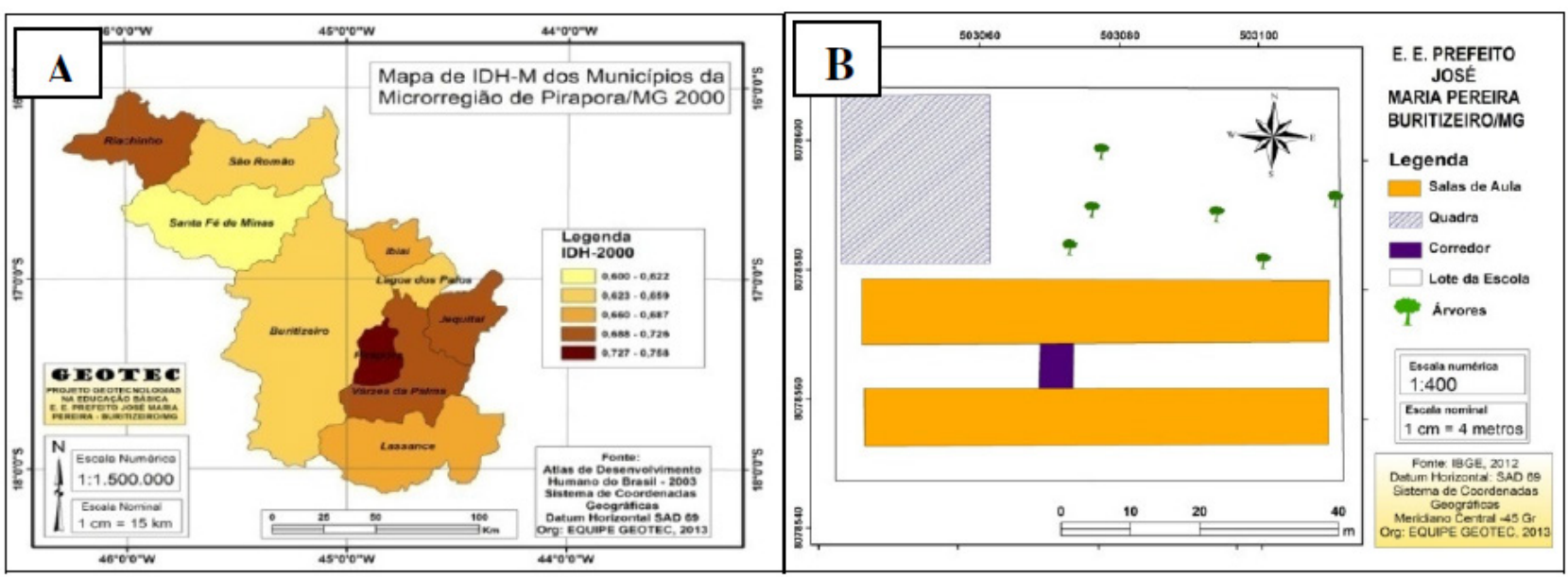

Figura 4 - A: Mapa representando o IDH dos municípios da microrregião de Pirapora/MG. B: Mapa da escola em visada vertical. Fonte: Atlas de Desenvolvimento Humano (4A) e Levantamento de campo pela Equipe Geotec (4B).

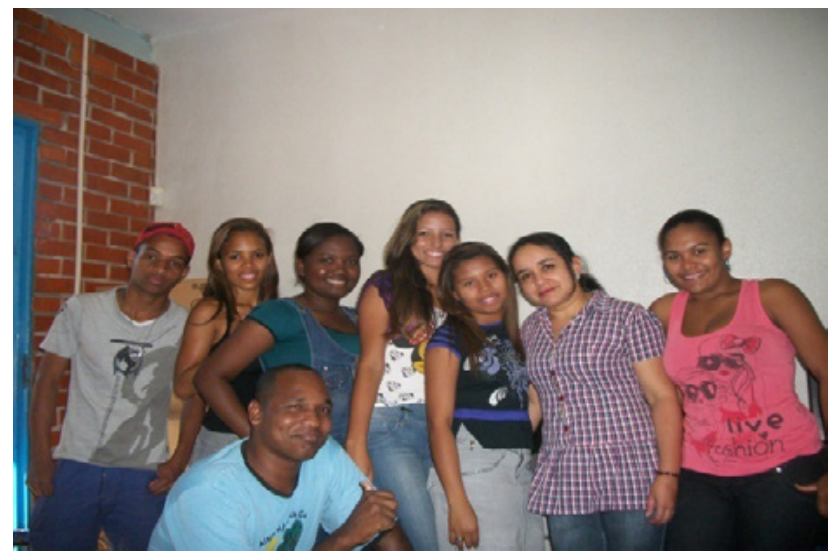

Figura5: Equipe GEOTEC, reunida para realização introdução às atividades. Inclui os alunos participantes, a professora regente e os dois acadêmicos (estagiários) inseridos no Projeto Fonte: FONSECA, S. F. (2013)

Ao finalizar o projeto apresentaram com facilidade conceitos que, no início nem mesmo imaginavam que existiam. Este projeto serviu de inspiração para a elaboração do Diamantina-SIG em meados de 2014.

\section{Projeto Diamantina-SIG}

A nosso ver a familiarização dos alunos com estatística descritiva e inferencial (foram elaborados alguns exercícios usando distribuição binomial de probabilidade), ainda que de forma superficial, foi de elevada importância. Possibilitou aos alunos a aquisição de novos conhecimentos (que raramente serão abordados em aulas do ensino médio da rede estadual e/ou pública de ensino) e que os auxiliarão futuramente, caso ingressem em curso superior. Além disso, demonstrou a necessária interdisciplinaridade que a geografia exige, sobretudo na área que envolve geoprocessamento, campo que apresenta profundos laços com a informática, matemática e estatística (ROSA, 2005; FONSECA et al. 2014).

Tarefas como aquisição e tratamento estatístico de dados, (para posterior inserção no software de SIG), foram realizadas pelos discentes (Figura 7).

Nas situações apresentadas nas fotografias acima, observa-se que os alunos estão adquirindo dados a serem trabalhos (A) e selecionando os municípios que estão inseridos no Vale do Jequitinhonha (B). Essa atividade proporcionou aos alunos maior envolvimento no uso do computador de maneira técnica, pois, muitas vezes a sala 
de informática é subutilizada devido a falta de preparação dos professores, que se sentem impotentes diante dessas situações (ABREU e SANTOS, 2011). Diante dos avanços técnicos e científicos que a sociedade passa em nossos dias, a apropriação de novas ferramentas tecnológicas tem se tornado elementar (PATTERSON, 2007) e nesse sentido, as escolas devem qualificar seus professores visando preencher essa lacuna.

Outro fator que merece destaque foi a motivação despertada nos alunos, frente ao uso de geoprocessamento na escola. (Figura 8A).

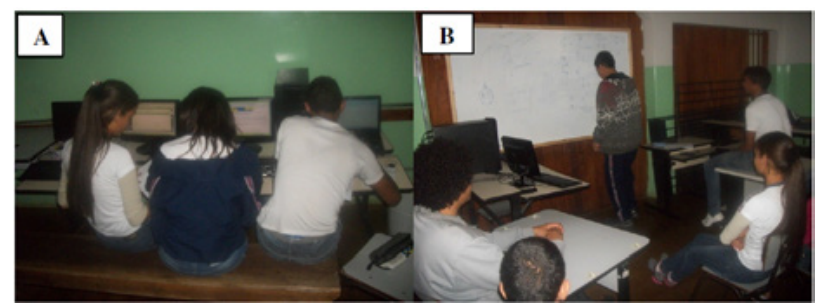

Figura 6 - A: Realização de atividade de Pesquisa usando internet B Alunos resolvendo questões de Estatística Básica. Fonte: FONSECA, S. F. (2014)

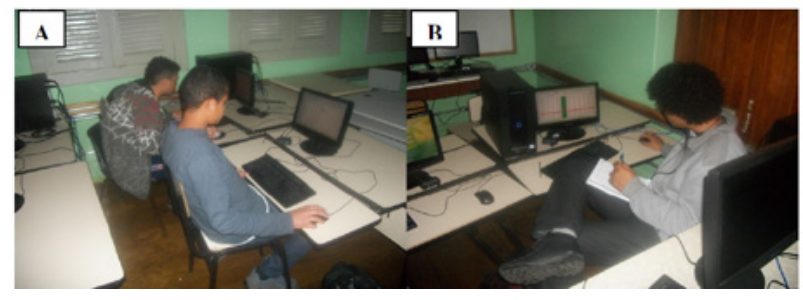

Figura 7 - A: Aquisição de dados usando internet B: Escolha dos municípios de interesse para o projeto Diamantina - SIG. Fonte: FONSECA, S. F. (2014)

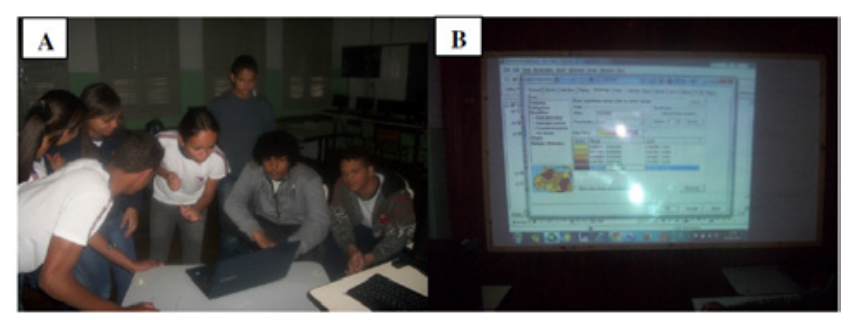

Figura 8 - A: Motivação despertada por Geoprocessamento B: Layout do aplicativo ArcGIS ${ }^{\text {TM }}$. Este software foi utilizado pelos alunos durante as atividades práticas.

Fonte: FONSECA, S. F. (2014)

$\mathrm{Na}$ Figura 8 (B) é apresentado o layout do ArcGISTM. Software de geoprocessamento, que os alunos utilizaram na elaboração dos mapas coropléticos. A preocupação com a aprendizagem inerente ao projeto (teoria e prática) mostrou que as atividades executadas no mesmo, foram suficientemente atraentes para envolver os alunos. A quebra de rotina nas aulas de geografia é sugerida por Fonseca et al. (2013b). Estes autores apresentam a necessidade de inserção de oficinas pedagógicas para que haja maior interação entre professor e aluno.

O site do Programa das Nações Unidas para o Desenvolvimento - PNUD (http://www.pnud.org.br/) disponibiliza os valores do IDH, bem como o Ranking nacional deste indicador. Esse site também disponibiliza gratuitamente o software do Atlas de desenvolvimento Humano, o qual apresenta um agrupamento de diversos indicadores sociais (PEA, GINI etc.). Os alunos do projeto Diamantina-SIG elaboraram mapas temáticos usando indicadores sociais IDH e índice GINI. (Figura 9).

\section{Comparando os projetos: Geotec x Diamantina-SIG}

Uma breve comparação entre os projetos será abordada a partir da participação ativa nos dois. No Geotec foram selecionados 5 (cinco) alunos e as atividades ocorreram no turno vespertino. Não houve desistência alguma, mas ocorreram dias em que as faltas prejudicaram o andamento das atividades. No Diamantina-SIG, participaram (10) dez estudantes e três desistiram devido à aplicação de atividade envolvendo estatística na fase inicial do projeto. O ponto positivo da introdução à estatística, se remete ao fato de proporcionar aos alunos uma leitura mais elaborada dos mapas coropléticos. Auxilia na compreensão desde o processo de preparação (onde é preciso escolher um procedimento estatístico adequado) até as conclusões, pós-elaboração. Conceitos como desvio padrão, mediana e média tornaram-se familiares para os integrantes do Diamantina-SIG. Por outro lado, as atividades que exigiam raciocínio matemático levou três deles à desistência.

Os integrantes do projeto Geotec possuíam mais maturidade. Eram alunos do último ano escolar e de idade pouco mais elevada (diferença média de 2 anos). Estes apresentaram o trabalho diante da turma na qual estavam inseridos e explicaram como as atividades foram desenvolvidas no decorrer do projeto. Os mesmos mostraram-se satisfeitos com a participação no Geotec. Embora as atividades tenham ocorrido fora do horário de aula, todos se comprometeram. Portanto, este modelo de projeto, mostrou-se mais apropriado que o Diamantina-SIG, neste último, nas datas de provas ou atividades semelhantes, os alunos não podiam ser liberados. Isto dificultou o adiantamento de algumas tarefas.

Em suma os dois projetos contribuíram na for- 
mação dos discentes. Tanto o projeto Geotec, quanto Diamantina-SIG foram relevantes. Nos dois foram trabalhadas habilidades essenciais ao uso da informática e geoprocessamento.
Além disso, foi realizada análise espacial com dados referentes à região na qual os alunos estão inseridos.
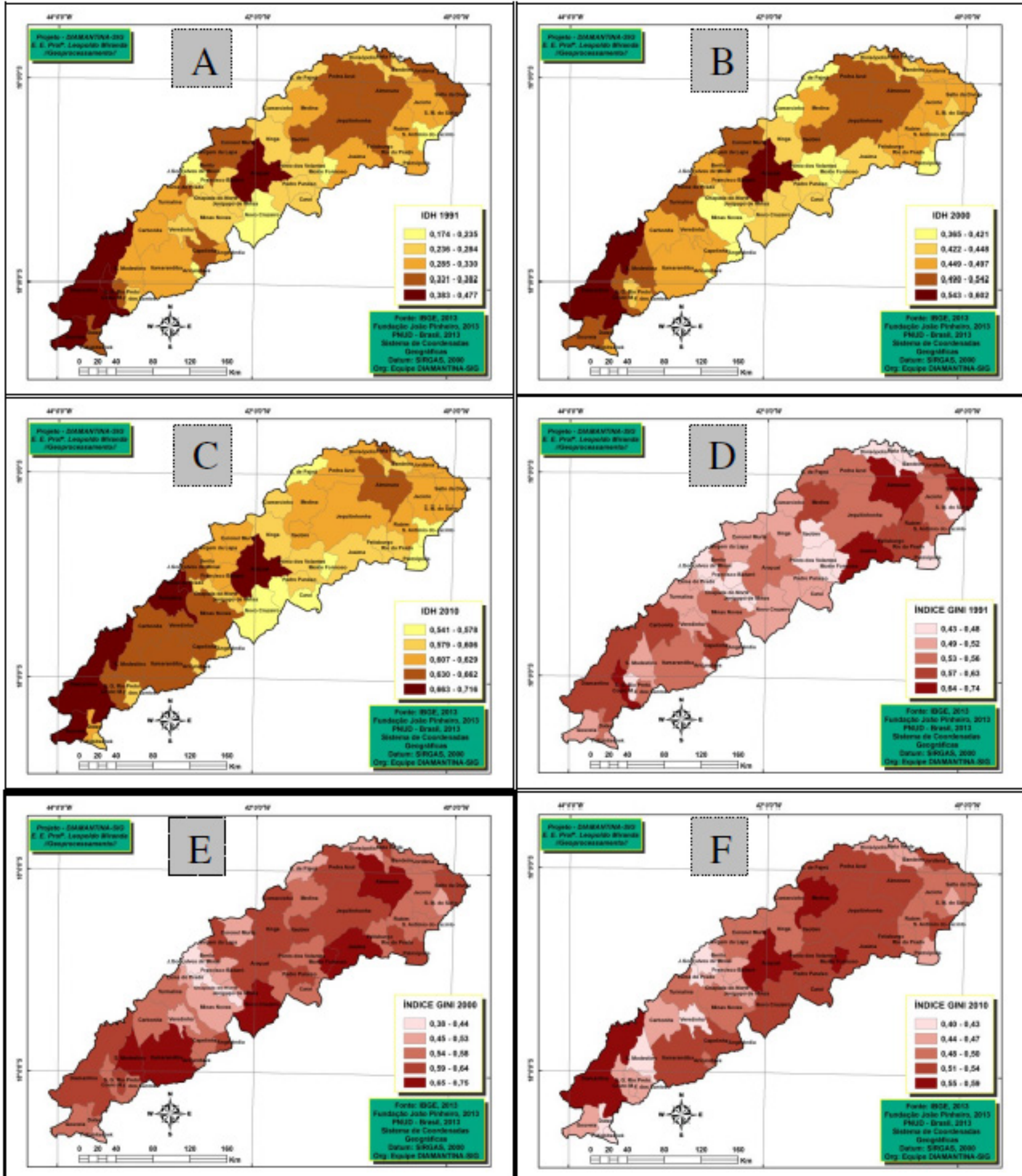

Figura 9: Mapas temáticos representando IDH (A, B, C) e índice GINI (D, E, F) dos anos1991, 2000 e 2010, dos municípios do Vale do Jequitinhonha, Minas Gerais, respectivamente.

Fonte: Projeto Diamantina-SIG. 
A nosso ver, foi dado um passo a mais rumo ao ensino emancipatório, onde os alunos estudam geografia de modo prazeroso construindo conhecimento a partir da realidade dos mesmos.

\section{CONCLUSÕES}

Ao executar o projeto Geotec, foi notável a necessidade que os alunos do ensino médio possuíam em relação ao uso da informática na escola. Isto sugere a intensificação de atividades escolares que possam envolvê-los com esta ferramenta. Exercícios de geoprocessamento, tornam-se potenciais para romper com a barreira entre o aluno e a informática. Além disso, cabe ao professor o acompanhamento mais rigoroso das atividades, que são denominadas "pesquisas", nas quais os alunos geralmente copiam e colam conteúdos sem no mínimo verificar a fonte (se confiável ou não).

No projeto Diamantina-SIG não foi diferente. Foram observadas dificuldades com tarefas básicas de informática, tais como executar um cálculo utilizando o Excel, prática corriqueira em vários ofícios. Foram detectados: desconhecimento de sites confiáveis para aquisição de respostas às tarefas sugeridas e ausência de contato com periódico científico. Estes fatos apontam a carência de uma abordagem científica mais aprofundada na escola básica.

Quanto ao distanciamento entre aluno e informática na escola, há várias condições a serem analisadas. Hoje os alunos utilizam as redes sociais diariamente, entretanto, este mesmo aluno que entende de "facebook" não conhece um periódico onde procurar bons artigos para estudar um tema científico ou mesmo elaborar um trabalho de qualidade. Dessa forma sugerimos a inserção de uma disciplina de metodologia científica a partir do primeiro ano do ensino médio.

Mediante o exposto, nota-se que o acesso a uma escola pública, que proponha ao corpo discente possibilidades de desenvolver maiores habilidades técnicas torna-se necessário. Projetos dessa magnitude, ainda que experimentais, oferecem novas oportunidades aos alunos mediante o uso das novas tecnologias e envolvimento com o universo científico.

O contato com geoprocessamento, informática e análise espacial é uma oportunidade elementar para que os alunos desenvolvam habilidades necessárias para atenderem ao atual mercado de trabalho. Não obstante, o convívio com a prática da geografia possibilita visualizar melhor essa ciência, que muitos ainda desconhecem sua aplicação.

\section{REFERÊNCIAS BIBLIOGRÁFICAS}

ABREU, T. C.; SANTOS, D. P. O uso do computador no processo ensino aprendizagem da Geografia Física, no $6^{\circ}$ ano do ensino fundamental. Revista Geográfica de América Central, n. esp. EGAL/2011 - Costa Rica, pp. 1-14. 2011.

BARROS, L. F. F.; CHAVES, M. S. Método fotocomparativo: uma proposta de construção do conhecimento geográfico no ensino básico. OKARA: Geografia em debate, v.5, n.1-2, p. 32-45. 2011.

FITZ, P. R. "Geoprocessamento no Ensino Médio". IN: ANAIS da VII Conferencia Iberoamericana Sobre Sistemas de Información Geográfica. Mérida, Venezuela 1999.

FONSECA, S. F. Geoinformação e análise da distribuição do IDH entre os municípios da microrregião de Pirapora-MG, usando Quantum GIS. IN: ANAIS do IV Congresso em Desenvolvimento Social - Mobilidades e Desenvolvimentos. 27 - 29 de agosto. Universidade Estadual de Montes Claros. 2014.

FONSECA, S. F.; GUEDES, C. R. M. Geoprocessamento, Ensino e Pesquisa: aplicação de projetos na educação básica. IN: ANAIS do V Congresso Norte-Mineiro de Pesquisa em Educação. Montes Claros - MG. Docências, Saberes Vivências. Montes Claros - MG: Editora Unimontes. 2013.

FONSECA, S. F.; MENDONCA, G. L. Uso de geoprocessamento em projetos na educação básica. Revista de Ensino de Geografia, v. 6, p. 5-19. 2015.

FONSECA, S. F; SANTOS, D. C.; HERMANO, V. M. Geoprocessamento aplicado á análise dos impactos socioambientais urbanos: estudo de caso do Bairro Santo Expedito em Buritizeiro/MG. Revista de Geografia (UFPE), vol. 30, n. 3, p. 178-191. 2013a.

FONSECA, S. F.; MENDONÇA, G. L.; SANTOS, D. C.; CARDOSO, V. F. Ensino de Geografia: uso e aplicação de oficina de cartografia enfatizando as formas de orientação. 
Geografia Ensino \& Pesquisa, Santa Maria/RS. vol. 17, n. 2, p. 147-156.DOI: 10.5902/22364994/10778. 2013b.

FONSECA, S. F.; SANTOS, D. C; MENDONÇA, G. L.; GUEDES, C. R. M. Sistemas de Informações Geográficas no ensino médio. Revista da Casa da Geografia de Sobral (RCGS), Sobral/CE, V. 15, n. 2, p. 32 - 46. 2013c.

FONSECA, S. F.; COTA, A. C.; GUEDES, C. R. M.; SANTOS, D. C. Sistema de Informações Geográficas na Educação Básica. IN: ANAIS do V Congresso Norte-Mineiro de Pesquisa em Educação. Montes Claros MG. Docências, Saberes Vivências. Montes Claros - MG: Editora Unimontes. 2013d.

FONSECA, S. F.; SANTOS, D. C.; TRINDADE, W. M. Técnicas de geoprocessamento aplicadas na classificação e avaliação da distribuição das espécies arbóreas nas praças de Buritizeiro/MG. Geografia Ensino \& Pesquisa, Santa Maria/RS. vol. 18, n. 2, p. 109-122. DOI: 10.5902/2236499412503. 2014.

FONSECA, S. F.; HERMANO, V. M.; SILVA, A. C. Mapeamento do uso da terra nos municípios de Janaúba e Nova Porteirinha (MG) usando dados de sensoriamento remoto. Élisèe - Revista de Geografia da UEG, v. 5, p. 103-119. 2016.

GIRÃO, O.; LIMA, S. R. O ensino de Geografia versus leitura de imagens: resgate e valorização da disciplina pela "alfabetização do olhar". Geografia Ensino \& Pesquisa, Santa Maria/RS. vol. 17, n. 2, p. 107-116. DOI: 10.5902/22364994/10774. 2013.

HOLGADO, F. L.; ROSA, K. K. Olhares sobre a paisagem - a utilização de imagens de satélite e fotografias aéreas no ensino de Geografia. Geografia Ensino \& Pesquisa, Santa Maria/RS, vol. 15, n.3, 129-138. 2011.

KOLVOORD, R. A.; UTTAL, D. H.; MEADOW, N. G. Using video case studies to assess the impact of the use of GIS on secondary students spatial thinking skills. Procedia: Social and Behavioral Sciences, 21, 372-379. doi:10.1016/j.sbspro.2011.07.039. 2011.

LAUDARES, S. Geotecnologia ao alcance de todos. Editora Appris. Curitiba, 2014.

PATTERSON, T. C. Google Earth as a (Not Just) Geogra- phy Education Tool. Journal of Geography, 106:4, 145152. DOI: 10.1080/00221340701678032. 2007.

PONTUSCHKA, N. N.et al. A disciplina escolar e os currículos de Geografia. IN: PONTUSCHKA, N. N.; PAGNELLI, T. I.; CACETE, N. H. (pp. 59 - 86). Para Ensinar e Aprender Geografia. São Paulo, Cortez, 2007.

RIBEIRO, E. Pesquisa e criatividade na formação do professor de Geografia. Geografia Ensino \& Pesquisa, Santa Maria/RS. vol. 17, n. 2, p. 107-116. DOI: 10.5902/22364994/10775. 2013.

ROSA, R. Geotecnologias na Geografia Aplicada. Revista do Departamento de Geografia, 16 (2005) pp. 81-90.

DOI: http://dx.doi.org/10.7154/RDG.2005.0016.0009. 2005.

SINGH, S. S. B.; KLEEMAN, G.; BERGEN, P. V. Opportunities to implement GIS in teaching and learning Geography: A survey among smart Schools in Sabah, Malaysia. Procedia: Socialand Behavioral Sciences, 69, 884 - 889. doi: 10.1016/j.sbspro.2012.12.012. 2012.

\section{Correspondência dos autores:}

$$
\begin{gathered}
\text { Samuel Ferreira da Fonseca } \\
\text { e-mail: fonsekageo@gmail.com } \\
\text { Carla Regina Mota Guedes } \\
\text { e-mail: carlareginalg@yahoo.com.br } \\
\text { DanniellaCarvalho dos Santos } \\
\text { e-mail: danniellacarvalho@gmail.com }
\end{gathered}
$$

Artigo recebido em: 13/10/2016

Revisado pelos autores em: 31/11/2016 Aceito para publicação em: 05/01/2017 